Short Note

\title{
Worst cases for a one-hop high frequency link
}

\author{
Gloria Miró $\left({ }^{1}\right)$, Benito A. de la Morena $\left({ }^{1}\right)$, Sandro Maria Radicella $\left({ }^{2}\right)$ and Miguel Herraiz $\left({ }^{3}\right)$ \\ (1) Atmospheric Sounding Station «El Arenosillo», National Institute of Aerospace Technology, \\ Magazón, Huelva, Spain \\ $\left(^{2}\right)$ Aeronomy and Radiopropagation Laboratory, Abdus Salam ICTP, Trieste, Italy \\ $\left(^{3}\right)$ Department of Geophysics and Meteorology, Faculty of Physics, Complutense University, Madrid, Spain
}

\begin{abstract}
The characterisation of a HF channel by means of monthly electron density profiles can be complemented with a detailed study of radio propagation «worst cases» on situations with extremes conditions of radiopropagation for a given period. These «worst cases» correspond to conditions that can be identified by means of cumulative distributions of the key parameter $f_{0} F_{2}$. This paper analyses the main parameters of the HF channel: time delay, apogee, elevation angle and transmission frequency with mean and extreme conditions. The method used to characterise the ionospheric channel is based on ray-tracing techniques.
\end{abstract}

Key words ionosphere - radio propagation - worst cases - ray-tracing

\section{Introduction}

An HF communication link is characterised by the Maximum Usable Frequency that is the limit above which the signal will not be reflected by the ionosphere under medium conditions. However, it is convenient to study all possible conditions. For this reason, an analysis of worst cases aimed at extending the results obtained by means of monthly median conditions to extreme ionospheric situations.

Mailing address: Dr. Gloria Miró, Atmospheric Sounding Station «El Arenosillo», National Institute of Aerospace Technology, 21130 Magazón, Huelva, Spain; e-mail: miroag@inta.es
The concept of worst cases was introduced in ray tracing techniques (Miró et al., 2000) to extend the channel characterisation to extreme ionospheric situations far from median conditions for HF links. Worst cases selection was performed using $f_{0} F_{2}$ through hourly cumulative frequency distributions.

The $2 \mathrm{D}$ ray tracing technique used (called abcray03), is based on the expressions introduced by Croft and Hoogasian (1968) and Croft (1969) and it has been considered in previous ionospheric studies (Moorhead and Radicella, 1998; Miró, 2000). The outputs obtained with this computing technique are the main radio propagation parameters: time delay of the signal travelling from the transmitter to the receiver, reflection height or apogee, elevation angle and transmission frequency. 
A particular ionospheric condition is introduce in the ray tracing program using model or experimental electron density profiles.

\section{Data}

As previously indicated, the parameter $f_{0} F_{2}$ was used to perform the worst cases selection through hourly cumulative frequency distributions. This study considered hourly revised $f_{0} F_{2}$ values from the digisonde DGS256 situated at El Arenosillo Atmospheric Station and the 19931997 period. An average of 1826 values was available for each $24 \mathrm{~h}$ and cut-off frequencies limiting $1 \%$ of these values with either the lowest or the highest frequencies have been chosen as worst cases conditions. For example, at $00 \mathrm{UT}$ hours $1 \%$ of cases had $f_{0} F_{2}$ lower than $2.4 \mathrm{MHz}$ and higher than 7.3 MHz. Once the worst cases selection has been done, the corresponding electron density profiles are introduced in the ray tracing technique.

\section{Methodology}

At each hour, profiles belonging to these upper/lower conditions are grouped to calculate a mean upper/lower extreme profile. This pro-
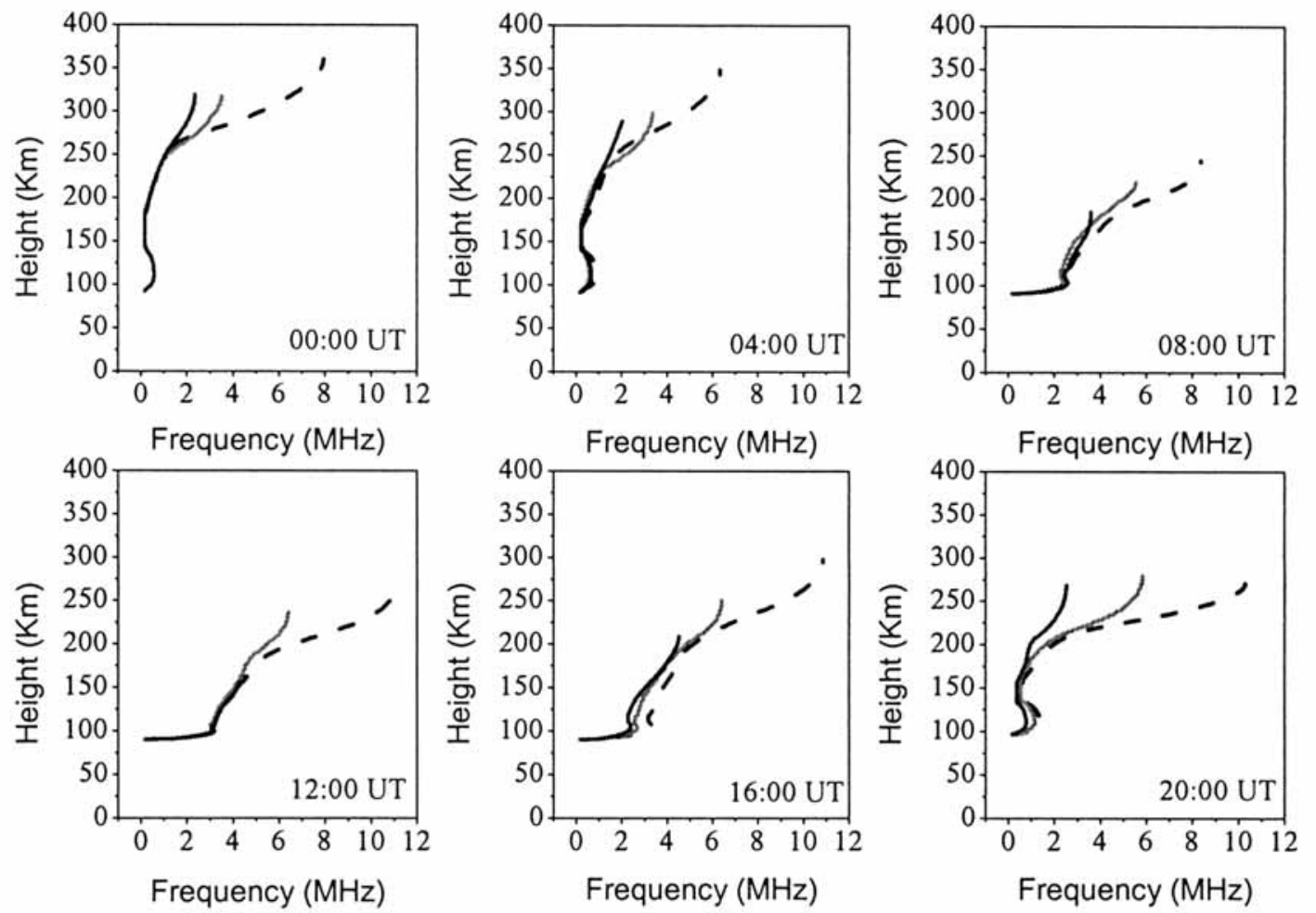

- - - Upper selection

Mean

\section{Lower selection}

Fig. 1. Hourly monthly electron density profiles and the corresponding to upper and lower selection at El Arenosillo Atmospheric Sounding Station. 
cedure provides three mean profiles per hour: upper extreme, lower extreme and hourly mean profile for all cases. These mean profiles were obtained following the methodology described in Huang and Reinisch (1996). Figure 1 shows an example of such profiles.

As has been noted, the ionospheric conditions in the reflection point necessary to characterise the HF channel are introduced by electron density profiles. It is important to point out that the profiles obtained after the worst case selection belong to one of the link extremes, El Arenosillo Station.

However, the particular link between El Arenosillo and Ebro Observatorio is situated at midlatitudes. Therefore, communications with a range close to $785 \mathrm{~km}$ correspond to one ionospheric hop with $E$ ( $E$ mode) or $F$ ( $F$ mode). Moreover, the ionospheric conditions at the reflection point which is located around the middle point in this specific link, can be approximate to data from one of the extremes, transmitter or receiver (Miró, 2000).

Using the three mean profiles at each hour (fig. 1), ionospheric conditions are introduced in the abcray03 program to derive at each $24 \mathrm{~h}$ the radio propagation parameters: transmission frequencies, elevation angles, time delays and apogees under extreme and standard situations.
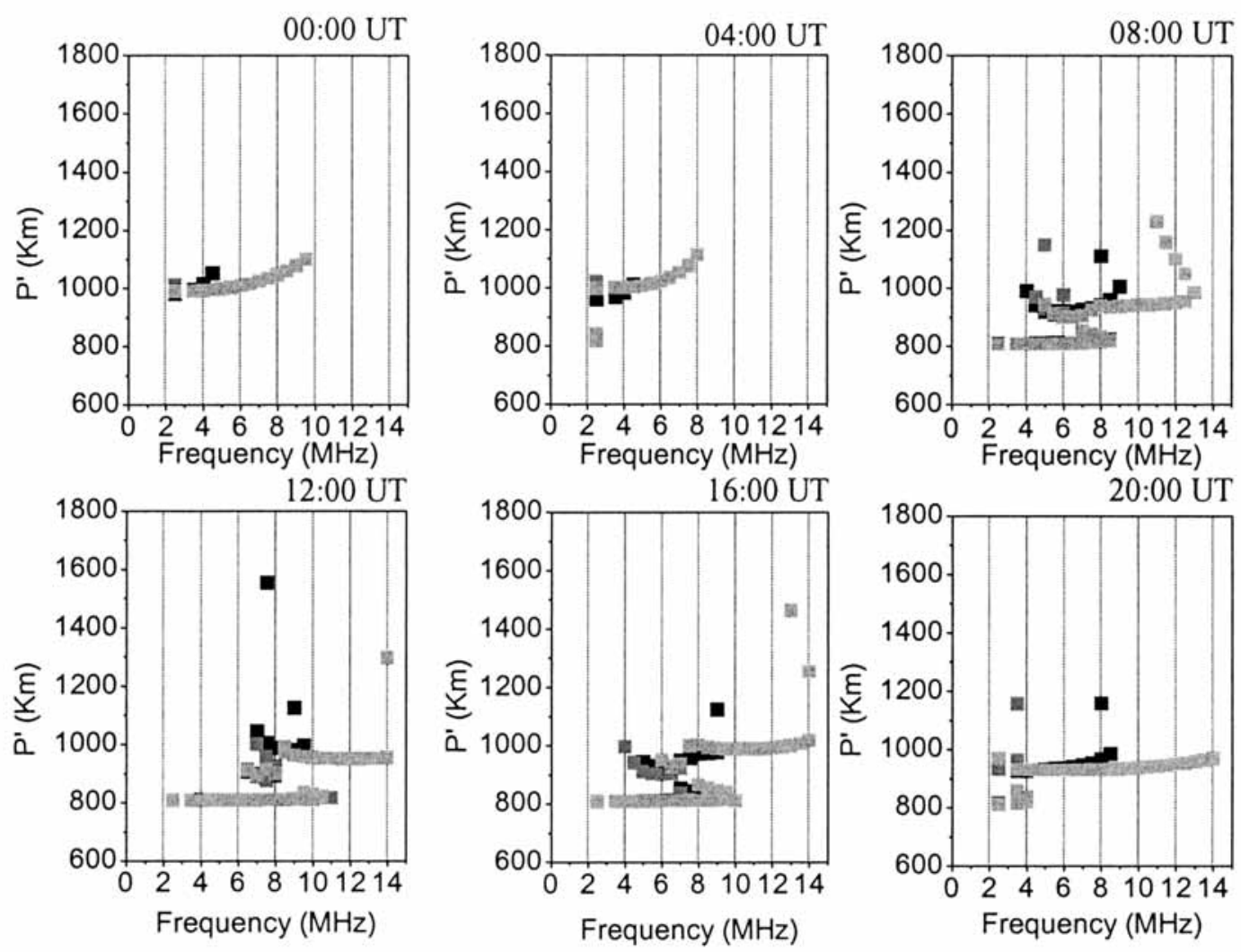

Fig. 2. Oblique ionograms obtained by abcray 03 program corresponding to upper, lower and mean conditions. 
Table I. Number of lower conditions cases which arrive at the receiver.

\begin{tabular}{cccccccc}
\hline \hline Hour $($ UT $)$ & Total & Lower & $\%$ & $E$ Mode & $\% E$ Mode & $F$ Mode & $\% F$ Mode \\
\hline $0: 00$ & 4 & 1 & 25 & 0 & 0 & 1 & 100 \\
$1: 00$ & 3 & 1 & 33 & 0 & 0 & 1 & 100 \\
$2: 00$ & 4 & 1 & 25 & 0 & 0 & 1 & 100 \\
$3: 00$ & 4 & 1 & 25 & 0 & 0 & 1 & 100 \\
$4: 00$ & 4 & 1 & 25 & 0 & 0 & 1 & 100 \\
$5: 00$ & 7 & 1 & 14 & 0 & 0 & 1 & 100 \\
$6: 00$ & 7 & 0 & 0 & 0 & 0 & 0 & 0 \\
$7: 00$ & 16 & 2 & 13 & 1 & 50 & 1 & 50 \\
$8: 00$ & 23 & 15 & 65 & 11 & 73 & 4 & 27 \\
$9: 00$ & 24 & 18 & 75 & 13 & 72 & 5 & 28 \\
$10: 00$ & 26 & 20 & 77 & 17 & 85 & 3 & 15 \\
$11: 00$ & 28 & 19 & 68 & 17 & 89 & 2 & 11 \\
$12: 00$ & 30 & 21 & 70 & 16 & 76 & 5 & 24 \\
$13: 00$ & 28 & 20 & 71 & 17 & 85 & 3 & 15 \\
$14: 00$ & 27 & 20 & 74 & 16 & 80 & 4 & 20 \\
$15: 00$ & 27 & 18 & 67 & 15 & 83 & 3 & 17 \\
$16: 00$ & 28 & 16 & 57 & 11 & 69 & 5 & 31 \\
$17: 00$ & 27 & 12 & 44 & 5 & 42 & 7 & 58 \\
$18: 00$ & 24 & 6 & 25 & 2 & 33 & 4 & 67 \\
$19: 00$ & 19 & 2 & 11 & 0 & 0 & 2 & 100 \\
$20: 00$ & 15 & 2 & 13 & 0 & 0 & 2 & 100 \\
$21: 00$ & 11 & 2 & 18 & 0 & 0 & 2 & 100 \\
$22: 00$ & 6 & 1 & 17 & 0 & 0 & 1 & 100 \\
$23: 00$ & 6 & 1 & 17 & 0 & 0 & 1 & 100 \\
\hline
\end{tabular}

\section{Results}

The distribution of the group path $P^{\prime}$ (proportional to time delay) versus the transmission frequency gives what is known as an oblique ionogram. Figure 2 displays synthetic oblique ionograms obtained with the ray tracing technique corresponding to some of the $24 \mathrm{~h}$ studied. Differences between the three conditions (upper extreme, lower extreme and mean) can be clearly seen mainly at $F_{2}$ heights.

From the HF communication systems point of view, the main problem is to find out the existence of low $f_{0} F_{2}$ on low electron density values. This situation is critical because this phenomenon reduces the Maximum Usable Frequency and the communication frequency band becomes narrower than that from mean and upper condi- tions (fig. 2). For this reason, special attention has been paid to the number of cases in which the signal arrives at the receiver in spite of the narrowing of the frequency range originated by low electron density conditions. Results are summarised in table I. As can be seen, only daylights hours (8:00 UT - 18:00 UT) provide an acceptable percentage of situations in which a link is established under all conditions. As expected, most of these signals belong to $E$ modes that do not appear during the rest of the hours. In general, if the daily transmission is done with a frequency between 6 and $8 \mathrm{MHz}$, the signal will reach the receiver under extremes and mean situations.

This study indicates that the characterisation obtained using ionospheric mean conditions can be applied in most situations. Only some cases 
during night hours can present problems if the transmission frequency used is near the Maxi-mum Usable Frequency because in these conditions, the signal will not be reflected by the low ionospheric electron density present in its ray path.

\section{Conclusions}

The main conclusion reached in this paper can be summarised as follows:

- In general, the characterisation obtained by means of monthly electron density profiles (Miró, 2000) could be applied even with extreme ionospheric conditions. The main problem can appear during night time for transmission frequencies close to the Maximum Usable Frequency.

\section{Acknowledgements}

The authors are grateful to Dr. Moorhead of Neptune Radar Ltd., Gloucester U.K., for his help in understanding the ray tracing technique, abcray03. This work has been possible thanks to financial support granted by the National Institute of Aerospace Technology (INTA).

\section{REFERENCES}

CROFT, T.A. (1969): Methods and applications of computer raytracing, Stanford Electronics Labs Tech., Report. SUSEL- 69-007.

Croft, T.A. and H. Hoogasian (1968): Exact ray calculations in a quasiparabolic ionosphere, Radio Sci., 3, 69-74.

HUANG, X. and B.W. REINISCH (1996): Vertical electron density profiles from digisonde ionograms - the average representative profile, Ann. Geofis., 39 (4), 751-756.

MIRó, G. (2000): Caracterización del canal ionosférico para un enlace HF punto a punto mediante técnicas de trazado de rayos, Ph.D. Thesis, Universidad Complutense de Madrid.

Miró, G., S.M. RADICELla, M. HERRAIZ, and B.A. DE LA MORENA (2000): Análisis de situaciones extremas para la caracterización del canal ionosférico en comunicaciones HF, in Tendencias Actuales en la Investigación de la Ionosfera, edited by M. HERRAIZ and B.A. DE LA MORENA, Colección Física de la Tierra, N. 12, Universidad Complutense de Madrid, 337-351. MoorheAD, M.D. and S.M. RADICELLA (1998): Using 2D raytracing to model the effects of vertical profile variability on oblique path propagation at HF frequencies, in Proceedings of the Side Workhop of COST 251. 